\title{
Familial median cleft of the upper and lower lips
}

INSERM

\section{Source}

INSERM. (1999). Orphanet: an online rare disease and orphan drug data base. Familial median cleft of the upper and lower lips. ORPHA:401942

Familial median cleft of the upper and lower lips is a rare and isolated orofacial defect characterized by incomplete median clefts of both the lower lip (limited to the vermilion, with no muscle involvement) and upper lip (with muscle involvement), double labial frenulum and fusion of the upper gingival and upper labial mucosa (resulting in a shallow upper vestibular fold), in addition to poor dental alignment, and increased interdental distance between the lower and upper median incisors. Variable expressivity has been reported in an affected family. 